\title{
Monitoring of Glucose in Beer Brewing by a Carbon Nanotubes Based Nylon Nanofibrous Biosensor
}

\author{
Marco Mason, Edoardo Longo, and Matteo Scampicchio \\ Faculty of Science and Technology, Free University of Bozen-Bolzano, Piazza Università 5, 39100 Bolzano, Italy \\ Correspondence should be addressed to Matteo Scampicchio; matteo.scampicchio@unibz.it
}

Received 25 March 2016; Revised 24 May 2016; Accepted 25 May 2016

Academic Editor: William Yu

Copyright ( 2016 Marco Mason et al. This is an open access article distributed under the Creative Commons Attribution License, which permits unrestricted use, distribution, and reproduction in any medium, provided the original work is properly cited.

\begin{abstract}
This work presents the design, preparation, and characterization of a novel glucose electrochemical biosensor based on the immobilization of glucose oxidase (GOX) into a nylon nanofibrous membrane (NFM) prepared by electrospinning and functionalized with multiwalled carbon nanotubes (CNT). A disc of such GOX/CNT/NFM membrane (40 $\mu$ m in thickness) was used for coating the surface of a glassy carbon electrode. The resulting biosensor was characterized by cyclic voltammetry and chronoamperometry, with ferrocene methanol as mediator. The binding of GOX around the CNT/NFM greatly enhances the electron transfer, which results in a biosensor with a current five times higher than without CNT. The potential usefulness of the proposed biosensor was demonstrated with the analysis of glucose in commercial beverages and along the monitoring of the brewing process for making beer, from the mashing to the fermentation steps.
\end{abstract}

\section{Introduction}

Electrochemical biosensors represent a milestone in the field of analytical electrochemistry. High chemo- and stereoselectivity, low manufacturing costs, thermal and chemical stability, and simplicity of construction are some of the attractive features that drive the research on the development of new electrochemical biosensors $[1,2]$. Among the different biosensors available, glucose biosensors have been one of the most successful examples due to the biomedical applications for diabetic patients [3,4]. So far, researches have focused on the development of biosensors with enhanced signal transduction, larger linearity range, and higher sensitivity [3-11]. The approach used has always been based on the improvement of signal transduction between flavin adenine dinucleotide (FAD), the redox species involved in the GOX kinetic, and an opportune transducer [12]. Overall, the process is a two-electron mechanism in which the reduction of FAD to $\mathrm{FADH}_{2}$ takes place at the expenses of glucose as the electrons donor [13]. Notably, in absence of oxygen only direct electrode oxidation of $\mathrm{FADH}_{2}$ can occur. The direct electron transfer kinetics of the oxidation of $\mathrm{FADH}_{2}$ by the electrode is hampered since FAD is buried $25 \AA$ deep from the outer protein surface, preventing the direct electron transfer with the electrode $[2,5]$. To circumvent this drawback, first-generation biosensors were based on the direct detection of the generated hydrogen peroxide (as $\mathrm{FADH}_{2}$ is reoxidized at the expenses of oxygen). Although the direct measurement of peroxide formation is attractive because it is simple and fast, the amperometric measurement requires large overpotentials. When biological samples are analyzed, the resulting response current may suffer from the interferences of coexisting electroactive species.

Second-generation biosensors overcame such limitations by replacing the oxygen with a reversible redox mediator that is able to shuttle the electrons from the redox center of the enzyme to the electrode surface (Figure 1).

A suitable mediator for the GOX enzyme is required to have a higher redox potential than the flavin redox center, so that it acts as the electron acceptor. For its fast reversibility and diffusion into interface layers, ferrocene methanol has been widely employed as the redox mediator of choice $\left(E^{0}\right.$ versus $\mathrm{Ag} / \mathrm{AgCl}=0.216 \mathrm{~V}, k^{0}=0.2 \mathrm{~cm} \cdot \mathrm{s}^{-1}$ ) [14]

Immobilization of the enzyme onto the electrode surface offers additional improvements. The advantage is that both enzyme and mediator can be brought close to the electrode surface, increasing the efficiency of the electron transfer 


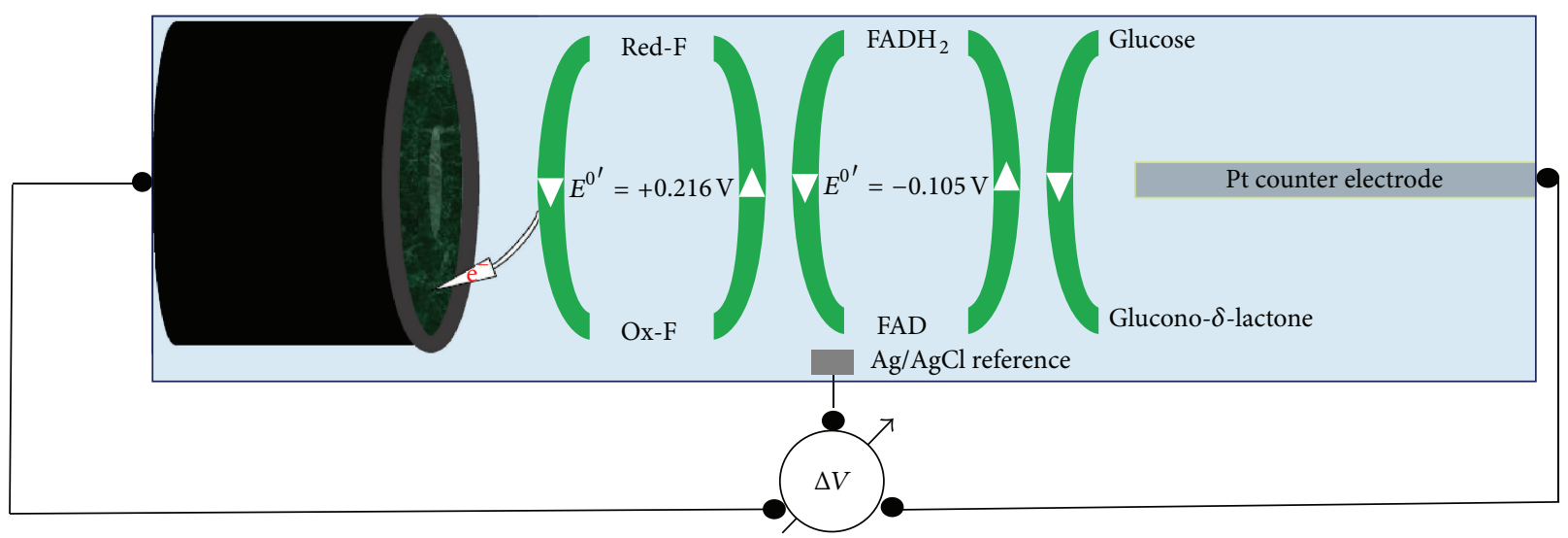

FIgURE 1: Typical oxidation mechanism of glucose with a second-generation biosensor based on a redox mediator. The picture shows the set-up used in this work, with the NFM-coated GGE. Red-F and Ox-F indicate reduced and oxidized ferrocene methanol, respectively.

between the enzyme and the electrode. Several methods of immobilization have been tested such as hydrogel encapsulation [4, 13-15], electropolymerization [16], or polymer film trapping [17-20]. Several improvements have also been devised in order to prevent unfavorable random orientations of the active site of the protein, such as templates or orienting functional groups [17, 20-25]. However, these approaches involve a certain effort to control the enzymes positioning to minimize the partial loss of catalytic efficiency due to active site wrong orientations.

A way to further enhance the electrochemical response has been to incorporate conductive elements between the electrode surface and the flavin redox center to enhance the heterogeneous electron transfer process. Carbon nanotubes (SWCNT or MWCNT) have been tested within biosensors, allowing both faster heterogeneous electron transfer and rigid scaffold orientation locking, for more efficient biosensors $[6,25-28]$. Some carbon nanostructures in particular show exceptional conductive properties. Moreover, polymer-CNT composites are easy to prepare and effectively displayed enhanced conductivity properties, along with better mechanical and thermal resistance [29-32]. Electrospinning (ES) has been recently applied as an intriguing way to prepare nanofibrous (NF) polymers with high surface-to-volume ratio. ES has gained attention in engineering and material science for its exceptional simplicity, low cost, and industrial applications [20,33]. Several reviews have been presented on this topic describing details on how this technique can be performed in-house by any laboratory [33-36]. Recent works in particular pointed out the good performances of electrospun Nylon-6 nanofibrous electrospun membranes (NFM) decorated with GOX for biosensing of glucose also in presence of interferents, showing good selectivity also in relatively complex matrices [6].

Glucose biosensors have a number of well-developed applications, from the biomedical (i.e., glucose monitoring for diabetic patients) to the pharmaceutical field. Also in food technology there are several potential applications where the features of glucose biosensors could provide a benefit for the producers. Apart from the classical analysis of glucose in fruit beverages, a very intriguing application of glucose biosensors could be the monitoring of glucose evolution and/or consumption during the production of alcoholic beverages, such as wine or beer. In particular, during beer brewing, the use of glucose biosensor could be of special help because it would provide information on the extent of the mashing process, where polysaccharides are progressively hydrolyzed into fermentable sugars, or during fermentation, where sugars are transformed into alcohol and carbon dioxide [37]. Thus, the simple and rapid monitoring of glucose could be of practical importance for the brew maker. In Table 1 some published results from glucose monitoring during several beer brewing steps and beer samples are reported.

Apart from brewing studies, a wide investigation of immobilized GOX for glucose sensing has been done [2, 5, 38]. Accordingly, this work aims to investigate the application of Nylon-6 nanofibrous electrospun membranes (NFM), functionalized with multiwall carbon nanotubes (CNT) and loaded with glucose oxidase (GOX) for the analysis of glucose content in fruit beverages and for the monitoring of glucose evolution in the beer brewing process.

\section{Materials and Methods}

GOX (from Aspergillus Niger Type XS, lyophilized powder, 100000-250000 units/g), salts, formic acid, and Nylon6 beads were purchased from Sigma-Aldrich and used as delivered. MWCNT were bought by Nano-Lab (Waltham, MA, US).

2.1. Carbon Nanotubes Preparation. MWCNT as delivered were treated in $6 \mathrm{M} \mathrm{HNO}_{3}\left(60^{\circ} \mathrm{C}\right.$ for $\left.16 \mathrm{~h}\right)$ and $8 \mathrm{M} \mathrm{HCl}$ $\left(80^{\circ} \mathrm{C}\right.$ for $\left.5 \mathrm{~h}\right)$ for activation. After pretreatment, MWCNT were recovered by centrifugation at $6000 \mathrm{rpm}$ for 15 minutes, washed in ethanol, ultrasonicated for 2 hours, and dried at $40^{\circ} \mathrm{C}$ for 5 to 16 hours until no weight loss was observed.

2.2. Electrospinning. Electrospinning (ES) was performed with an in-house apparatus based on a Spellman ${ }^{\circledR}$ CZE 1000R 


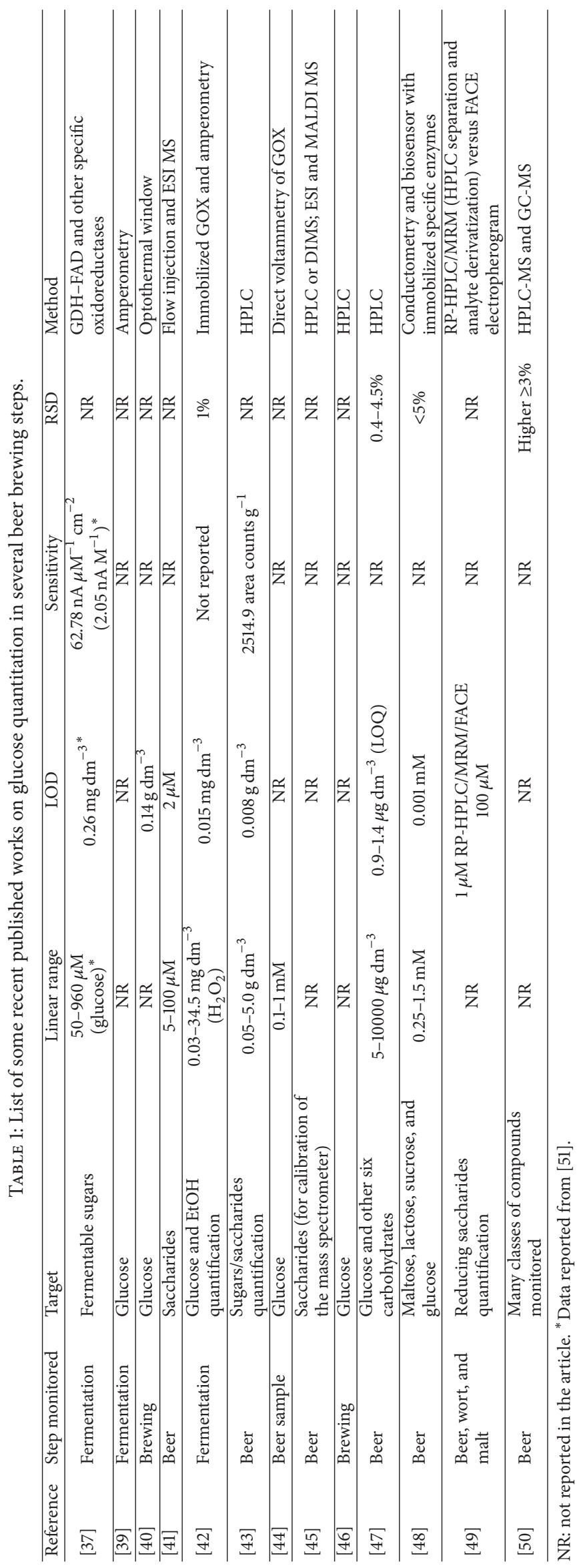


potentiostat equipped with a syringe pump. All NFM were electrospun at a flux of $0.02 \mathrm{~mL} / \mathrm{min}$ onto an aluminium foil that acted as a grounded collector, when a $+25 \mathrm{kV}$ potential was applied on the flux exit needle located at $13 \mathrm{~cm}$ distance. Humidity in the environment was kept below $40 \%$ throughout the procedure. The NMF were functionalized with MWCNT by in-solution dipping. The resulting composite was analyzed by SEM (Figure SI 4 in Supplementary Material available online at http://dx.doi.org/10.1155/2016/5217023). Comixing the polymer precursor solution with MWCNT was also undertaken but it did not yield a viable way in terms of NFM strength and membrane conductivity; therefore this approach is not discussed any further herein. Immobilization of the enzyme was achieved by means of glutaraldehyde as the cross-linker, in presence of bovine serum albumin. This approach was adapted from a published methodology [6].

\subsection{Functionalization of NFM with MWCNT Coating. A} weighed amount of NFM $3.8 \mathrm{mg}$ (2 sides of $9.62 \mathrm{~cm}^{2}$ ) with a thickness of $0.04 \pm 0.01 \mathrm{~mm}$ was dipped into a $50 \mathrm{mM}$ Triton ${ }^{\mathrm{TM}} \mathrm{X}-100$ solution containing a pretreated and sonicated MWCNT dispersion with concentration of $0.5 \mathrm{mg} \cdot \mathrm{mL}^{-1}$. The mixture was ultrasonicated for 10 hours a day for one week $\left(50 \mathrm{~W}, 40 \mathrm{kHz}\right.$ at $\left.25^{\circ} \mathrm{C}\right)$; then the membrane was removed and dried at $50^{\circ} \mathrm{C}$ for 20 minutes, carefully plunged in milliQ water until surfactant rinsing and dried again at $50^{\circ} \mathrm{C}$ for 30 minutes. After reweighing the membrane coated with MWCNT, the final amount deposited on the membrane was $4.5 \%$ of initial weight. The final membrane presented a homogeneous black coating.

2.4. Scanning Electron Microscopy. NFM scanning electron micrographs were collected on a Phenom ${ }^{\mathrm{TM}}$ ProX SEM instrument (70-20000x digital zoom) with $30 \mathrm{~nm}$ max resolution. Samples were mounted on aluminium stubs and images were collected at 5 or $10 \mathrm{kV}$ accelerating voltage. All samples were mounted on biadhesive tape and purged with a gentle air flow prior to measurement. Fibers diameter dispersion was evaluated with the provided Phenom Pro Suite using the Fibermetric tool. Average diameter distributions were evaluated by fitting with a Gaussian function.

2.5. Electrode Coating. A bare glassy carbon working electrode (BAS) was first polished with 0.3 and $0.05 \mu \mathrm{m}$ alumina slurry, then rinsed with water, and sonicated in EtOH, till a mirror-like surface was obtained. A piece of Nylon-6 NFM prepared as described before was placed on top of the electrode surface and fixed with two O-rings (all membrane exceeding parts were carefully cut off).

2.6. Enzyme Immobilization. An enzyme solution was prepared in two steps: first, $40 \mathrm{mg}$ of BSA and $11.4 \mathrm{mg}$ of GOX were dissolved in $1 \mathrm{~mL}$ of Britton-Robinson $\mathrm{pH}$. Then glutaraldehyde $(5 \mu \mathrm{L}, 2.5 \%)$ in water was added to $15 \mu \mathrm{L}$ of this solution. The coating solution was freshly prepared before electrode coating. $5 \mu \mathrm{L}$ was dropped twice to the center of the membrane and left drying for 10 minutes at room temperature. After the immobilization, the biosensor was placed in Britton-Robinson $\mathrm{pH} 5$ and stored at $4^{\circ} \mathrm{C}$.

2.7. Electrochemical Characterization. CV experiments were performed using an AUTOLAB $128 \mathrm{~N}$ potentiostat. A $0.07 \mathrm{~cm}^{2}$ glassy carbon working electrode, $\mathrm{Ag} / \mathrm{AgCl}$ reference, and $1 \mathrm{~cm}^{2}$ Pt counter electrode (BAS) were used in $0.4 \mathrm{M}$ Britton-Robinson buffer at room temperature. Cyclic voltammetry was performed in the range from $-0.2 \mathrm{~V}$ to $+0.6 \mathrm{~V}$. $100 \mu \mathrm{M}$ Ferrocene methanol was used as mediator, with or without the presence of glucose. Chronoamperometric measurements were performed under stirring at an applied potential of $+0.5 \mathrm{~V}$ with a $0.5 \mathrm{~s}$ per point acquisition time.

2.8. Determination of Glucose with the Dinitrosalicylic Acid (DNS) Reagent. The reagent was prepared by adding $5 \mathrm{~g}$ of DNS salt in $200 \mathrm{~mL}$ of distilled water containing $150 \mathrm{~g}$ of potassium sodium tartrate tetrahydrate and $8 \mathrm{~g}$ of sodium hydroxide. Care was taken by first mixing the tartrate and $\mathrm{NaOH}$ solutions and then adding the DNS salt. The solution was left overnight under stirring. The following day, a final volume of $500 \mathrm{~mL}$ was reached by adding distilled water [52]. An aliquot of standard or sample was diluted to $2 \mathrm{~mL}$ with deionized water and mixed with $2 \mathrm{~mL}$ of DNS reagent. Before UV-VIS measurement, the solution was heated in boiling water for 3 minutes. The determination was performed on an Agilent Cary 100 spectrophotometer provided with a Peltier thermostated 12 -cell unit at $25^{\circ} \mathrm{C}$. The spectra were collected between 500 and $650 \mathrm{~nm}$ ( $2 \mathrm{~nm}$ bandwidth, 1 point per sec integration time). The measurements of each standard or sample were repeated in triplicate. Sample concentrations were calculated by taking into account dilution factors.

2.9. Beer Preparation and Glucose Analysis. The beer making process has been monitored throughout the brewing steps. The samples have been collected in the following steps. (1) Malt (500 g) was milled (mill rollers knurled stainless steel AISI 316$)$ and then added to warm water $\left(1.5 \mathrm{~L}, 52^{\circ} \mathrm{C}\right) .(2)$ The temperature was kept at $52^{\circ} \mathrm{C}$ for 15 minutes. In this step, the proteases contained in the malt provide a source of free amino acids, which are being used later by the yeast during fermentation. (3) The temperature was raised to $62^{\circ} \mathrm{C}$ and kept for 10 minutes (maltose production). (4) This was followed by a further raise at $68^{\circ} \mathrm{C}$ that was kept for 30 minutes (saccharification). In steps (3) and (4) the $\alpha$ - and $\beta$-amylases break down starch molecules into fermentable sugars (i.e., glucose and maltose). (5) The temperature was further raised at $78^{\circ} \mathrm{C}$ and kept for 15 minutes to inactivate the enzymes. (6) Then, the wort was filtered and washed with water (about $500 \mathrm{~mL}$ ). (7) The sweet wort was then boiled for $1 \mathrm{~h}$, during which $2.8 \mathrm{~g}$ of hops was added (Hallertau Hersbrucker). After boiling, the hops were removed and the wort rapidly cooled down to room temperature thanks to a heat exchanger. Then $1 \mathrm{~g}$ of yeast (Danstar Nottingham British Ale) was added for starting the fermentation (fermentation day 0 ). The fermentation was monitored for additional 4 days (steps (8) and (11)). The evolution of glucose during the fermentation was monitored. Wort samples were filtered 


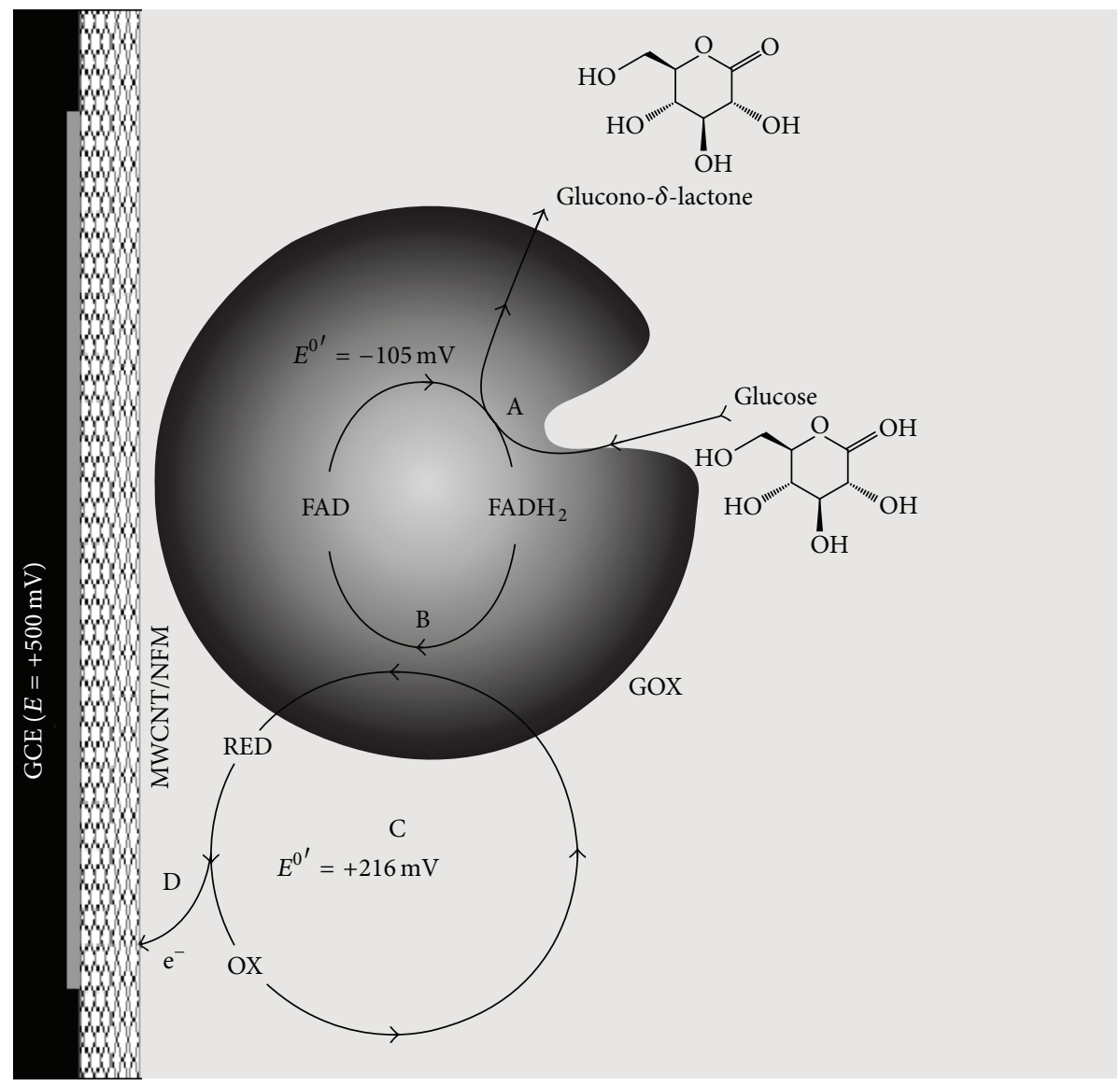

FIGURE 2: Sensing mechanism. OX and RED are the oxidized and reduced mediator forms, respectively.

with a $0.2 \mu \mathrm{m}$ CA membrane. $1 \mathrm{~mL}$ or $1.5 \mathrm{~mL}$ of the filtered solution was then added to the biosensor measurement cell prepared with $10 \mathrm{~mL}$ of $100 \mu \mathrm{M}$ ferrocene methanol solution. The response current was read after at least $200 \mathrm{~s}$ of plateau equilibration.

\section{Results and Discussion}

3.1. Characterization of the GOX-NFM/MWCNT by Cyclic Voltammetry. The sensing mechanism for this secondgeneration GOX biosensor is schematically described in Figure 2.

Briefly, glucose is converted to gluconate (A) by reducing FAD into $\mathrm{FADH}_{2}$ (FAD reduced form). $\mathrm{FADH}_{2}$ is oxidized back (B) by the mediator (e.g., ferrocene methanol) which becomes reduced (C). FAD becomes this way available again to accept electrons from glucose. The reversible mediator is free in solution and can get closer to the anode. Therefore, it is oxidized at the coated electrode directly and through mediation of the carbon nanotubes (D). It becomes again available this way for reduction by $\mathrm{FADH}_{2}$. The overall effect provided by carbon nanotubes in ET enhancement has been elucidated and consists in a better current transduction [53, 54]. To show the effect of added MWCNT on our biosensor,
Figure 3 compares the effect of CNT on the resulting mediated detection of glucose by ferrocene methanol. In detail, when the electrode is coated with NFM and loaded with GOX, the resulting voltammogram reflects the typical response of a mediated biocatalytic reaction, where the reversible voltammetry of the mediator turns irreversible with the anodic current reaching a plateau at potential higher than $+0.2 \mathrm{~V}$ versus $\mathrm{Ag} / \mathrm{AgCl}$. Upon reversing the direction of potential scan, no reduction peak is observed, as expected when the oxidized form of the mediator is rapidly consumed by the continuous oxidation of $\mathrm{FADH}_{2}$ (Figure 3(a)). When the NFM was functionalized with CNT and the enzyme was free in the bulk solution, the result is similar but the background current is increased. The prominent background current is a consequence of the large, catalytically active surface area of the modified electrode. Apart from the higher capacitive current, the signal enhancement is negligible (Figure 3(b)). However, when the glassy carbon electrode is coated with NFM functionalized with CNT and loaded with glucose oxidase, a great enhancement on the current response is observed (Figure 3(c)). Since such higher current density is observed only when the enzyme is immobilized on the conductive surface of the NFM functionalized with CNT, we conclude that such enhancement is due to the electron 


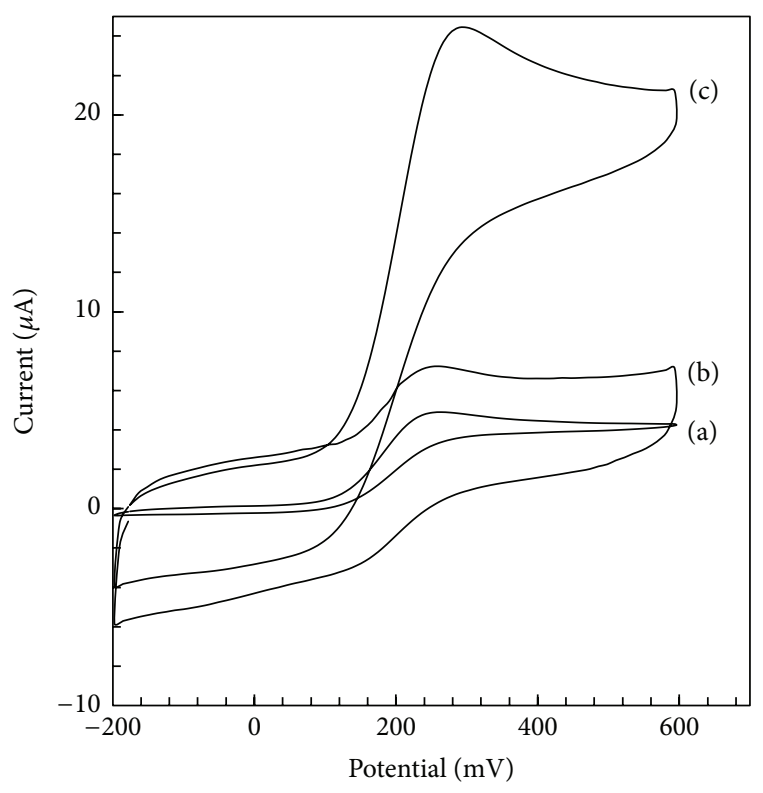

FIGURE 3: Cyclic voltammetry of glucose at a glassy carbon electrode coated with (a) NFM with GOX immobilized; (b) NFM/CNT with GOX free in solution; (c) NFM/CNT with GOX immobilized. Experiment: $25.2 \mathrm{mM}$ D-glucose, $100 \mu \mathrm{M}$ ferrocene methanol, and Britton-Robinson buffer, $400 \mathrm{mM}, \mathrm{pH}$ 5. Detection was performed at $100 \mathrm{mV} \mathrm{s}^{-1}$ scan rate. A full characterization of anodic peak current versus the scan rate and evaluated diffusion coefficients are reported in Supporting Information (Table SI 1 and Figure SI 1).

shuttling of CNT from the active site of GOX toward the glassy carbon transducer [53].

3.2. Analytical Performance of the Biosensor by Chronoamperometry. Chronoamperometry is a very sensitive technique for electrochemical biosensors characterization. In order to evaluate the analytical performance of the glassy carbon electrode coated with NFM/CNT/GOX, Figure 4 shows the chronoamperometric calibration of glucose in presence of $100 \mu \mathrm{M}$ ferrocene methanol.

Although the GOX enzyme amount was the same both with loaded CNT and without, the effect of the biosensor design on the resulting signal intensity was huge. With respect to both the system with no immobilized enzyme and the one with no MWCNT loaded, NY CNT + imm GOX displayed a much higher response to glucose additions. Notably, all points correspond to $10 \mu \mathrm{L}$ additions. As we discussed before, the addition of nanotubes (SWCNT or MWCNT) enhances the efficiency of the biosensor by increasing the electron transfer. This is consistent with our data. In fact, also with free GOX (purple curve) nanotubes induce a higher response. This effect can be seen by the higher plateau currents at the highest concentrations. On the contrary, the only immobilization of the enzyme has a little effect on the overall current even if it can extend the linearity range against glucose addition [6]. Under optimized conditions, the glassy carbon electrode coated with NFM/CNT/GOX showed a linearity range from 1 to $3 \mathrm{mM}\left(R^{2}=0.98\right)$. In

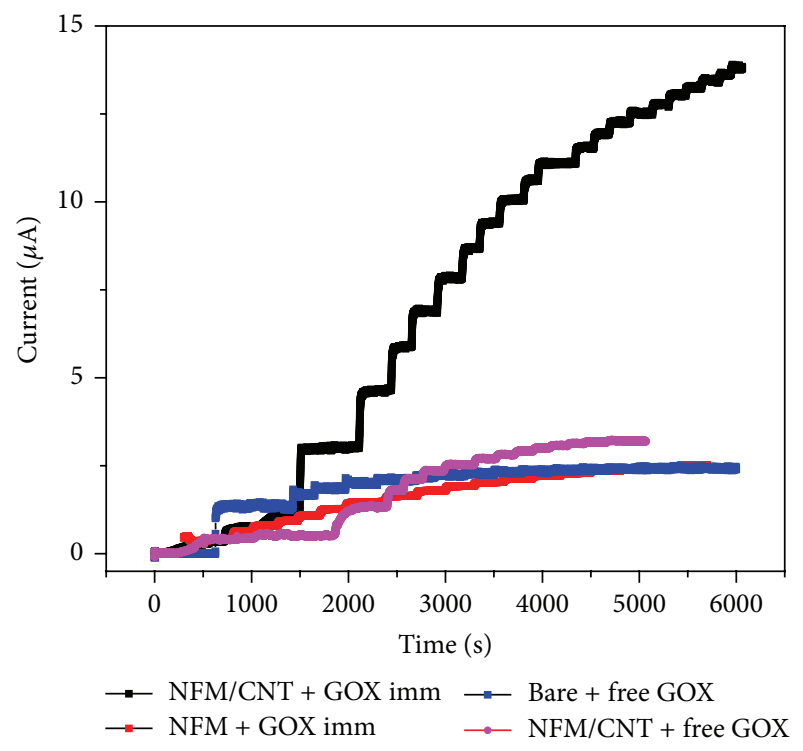

FIGURE 4: Chronoamperometry current $(\mu \mathrm{A})$ versus time (s) plots at the different preparation stages $(\mathrm{NFM} / \mathrm{CNT}+\mathrm{GOX} \mathrm{imm} ; \mathrm{NFM}+$ GOX imm; bare + free GOX; NFM/CNT + free GOX). Comparison with CNT and immobilized and free GOX at day 0 . Conditions used: $100 \mu \mathrm{M}$ ferrocene methanol in $400 \mathrm{mM}$ Britton-Robinson buffer $\mathrm{pH}$ $5 ;+0.5 \mathrm{~V}$ applied potential; 1 point/sec; constant $10 \mu \mathrm{L}$ additions.

such range the sensitivity was $1.2 \mu \mathrm{A} \cdot \mathrm{mM}^{-1}(\mathrm{RSD} \%=2 \%)$ with a limit of quantitation of $20 \mu \mathrm{M}(\mathrm{S} / \mathrm{N}=10)$. Although the linear range was smaller than the one reported with a similar biosensor [6], the sensitivity was four times higher. Such higher sensitivity is a direct consequence of the loading of CNT on the surface of the nanofibers.

3.3. Kinetic Behavior of GOX-NFM/MWCNT and Effect of $p H$, Interferents, and Ageing. The kinetics of the enzyme before and after its immobilization on the NFM/CNT was studied by chronoamperometry for increasing concentration of glucose $(0-12 \mathrm{mM})$ and at several $\mathrm{pH}$ values. As an example, Figure 5 shows the resulting current versus concentration plots at $\mathrm{pH}$ 5. The experimental points were initially fitted with a classical Michaelis-Menten model. Unfortunately, only when the enzyme was free in solution, the resulting current response obeyed this model. Conversely, when GOX was immobilized on the NFM, the current response showed a sigmoidal trend. The trend is fitted instead very well with the Hill equation, a generalized Michaelis-Menten model.

The effect of $\mathrm{pH}$ on immobilized GOX kinetics was investigated between 5 and 7. For the free GOX, the optimum has been found between these values, and for immobilized GOX the values have been found below 6 and above 7, depending on the preparation $[1,51,55]$. In our case the optimum was found between 5 and 6 and the minimum value at 6.5. The Michaelis-Menten model did not fit the whole dataset properly. In fact, the current response for glucose concentrations below $1 \mathrm{mM}$ deviates from linearity. Therefore, the Hill equation was alternatively applied to evaluate the asymptotes of the curves, namely, the $V_{\mathrm{MAX}}^{H}$ 


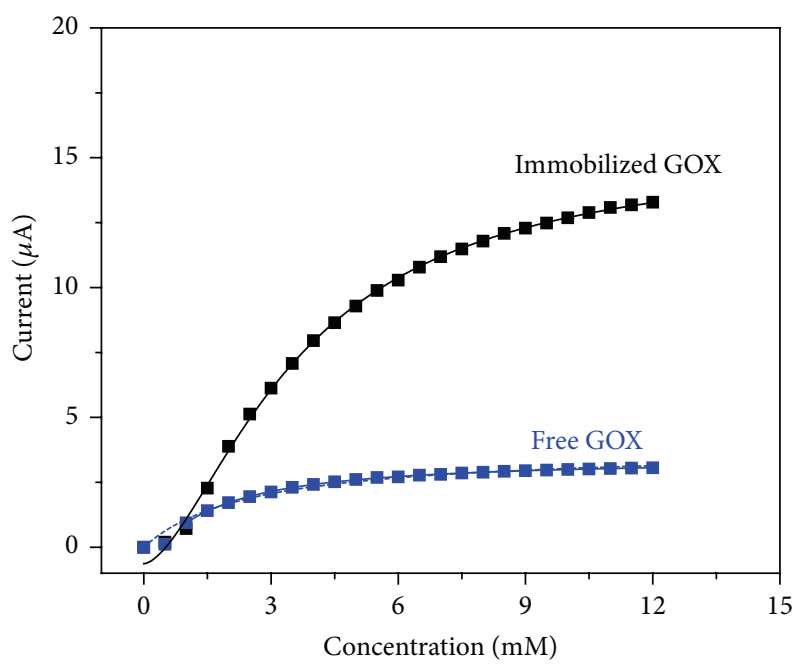

FIGURE 5: Chronoamperometric current responses of the biosensor with the GOX free or immobilized on the NFM/CNT, for increasing concentration of glucose. In the case of the GOX free in solution (NY CNT + free GOX), experimental points were fitted with MichaelisMenten equation: $y=V_{\mathrm{MAX}} * x /\left(K_{M}^{\mathrm{app}}+x\right)$, where $V_{\mathrm{MAX}}=(3.8 \pm$ $0.1) 10^{-6}$ and $K_{M}^{\text {app }}=2.53 \pm 0.23$. In the case of GOX immobilized on the NFM/CNT, the points were fitted with a Hill type equation: $y=\mathrm{START}+(\mathrm{END}-\mathrm{START}) * x^{n} /\left(k^{n}+x^{n}\right)$, where START $=(-4.1 \pm$ $1.7) 10^{-7}, \mathrm{END}=(1.52 \pm 0.03) 10^{-5}, K_{H}=3.64 \pm 0.1$, and $n=1.6 \pm 0.1$. In both cases, $R^{2}$ was 0.998 . For the Michaelis-Menten fitting of NY $\mathrm{CNT}+\mathrm{imm}$ GOX $K_{M}^{\mathrm{app}}=6.7 \pm 0.6 \mathrm{mM}, V_{\mathrm{MAX}}=23.04 \pm 1.62 \mu \mathrm{A}$ (fitting was bad; therefore it is not shown).

values ( $V_{\text {MAX }}$ of Hill model): $4.96 \pm 0.20 \mu \mathrm{A}, 3.17 \pm 0.04 \mu \mathrm{A}$, $8.05 \pm 0.35 \mu \mathrm{A}, 1.86 \pm 0.03 \mu \mathrm{A}$, and $3.84 \pm 0.05 \mu \mathrm{A}$ at $\mathrm{pH}$ values $5,5.5,6,6.5$, and 7 , respectively (data collected at the same ageing time on the same system equilibrated at the $\mathrm{pH}$ required). The reason for analyzing $V_{\mathrm{MAX}}^{H}$ is that $K_{M}^{\mathrm{app}}$ corresponds to one-half of the concentration required for the enzyme to reach the conversion speed limit (the asymptote or $V_{\text {MAX }}$ ). Therefore, $V_{\text {MAX }}^{H}$ (the actual experimental limit) can account qualitatively for the efficiency of the enzyme. This trend is not trivial to discuss. More investigations will be required to elucidate the lack of a precise trend in efficiency moving away from $\mathrm{pH} 6$. We carried out the analyses at $\mathrm{pH}$ 5 instead of $\mathrm{pH} 6$ because of the wider linear range. For the linear fitting of the $1-4 \mathrm{mM}$ range at $\mathrm{pH} 5 \mathrm{R}^{2}$ was 0.98 and at $\mathrm{pH} 6$ was 0.94 . At $\mathrm{pH} 6, R^{2}$ was near 0.98 only in the 1-2 $\mathrm{mM}$ range. Just for a comparison with other published results, we calculated the apparent Michaelis-Menten $K_{M}^{\text {app }}$ constant at $\mathrm{pH} 5$ that was $6.7 \pm 0.6 \mathrm{mM}$. This constant accounts for the enzyme efficiency and the found value is in good agreement with others reported in literature [9]. However, the immobilization strategy and the biosensor design can affect the enzyme efficiency so that much higher $K_{M}^{\mathrm{app}}$ values are possible (e.g., $44 \mathrm{mM}$ ) [56]. Since the MM model did not fit the data and a generalized model (i.e., Hill equation) was used instead, we hypothesized the presence of a barrier-todiffusion stage that the substrate has to overcome at lower concentrations. When the concentration of glucose is low, the substrate diffusion toward the "pseudo" pores of NFM

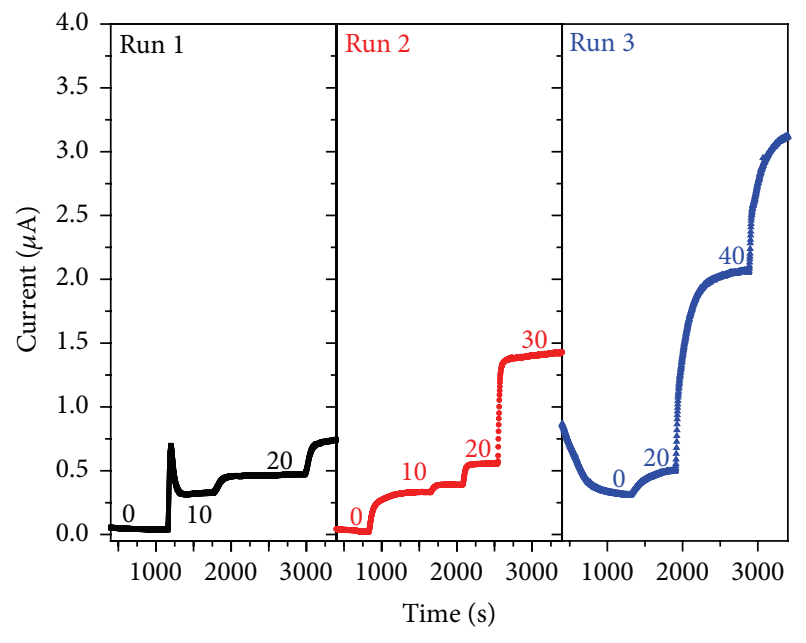

FIGURE 6: Three repetitions (black, red, and blue) of glucose calibration performed with a membrane stored for 45 days, using different initial additions volumes $(\mu \mathrm{L})$. Numbers represent volumes $(\mu \mathrm{L})$ of $0.5 \mathrm{M}$ glucose added. Data not corrected for $100 \mu \mathrm{M}$ ferrocene methanol current (which account for the initial higher $0 \mu \mathrm{L}$ point current in run 3 ).

is very limited. Only when glucose is higher than $1 \mathrm{mM}$, the transduction efficiency of the enzyme becomes linearly related to its concentration.

Such biased response, low signal intensity for low concentration of the substrate and high sensitivity for concentrations higher than about $1 \mathrm{mM}$, was invariant for the amount of substrate added. Figure 6 shows the current response of the electrode coated with NFM/CNT/GOX for different initial (up to $1.5 \mathrm{mM}$ ) single spikes of $0.5 \mathrm{M}$ glucose. The resulting calibration plot was the same when the spikes were done every 20 or $10 \mu \mathrm{L}$ of $0.5 \mathrm{M}$ glucose, and the plateau currents (above $20 \mu \mathrm{L}$ ) show a good agreement with the linear trend (see Figure SI 2 where the same data in the whole linear range are shown).

The biased response observed for lower concentration of glucose was not ascribable to the loss of enzyme morphology. Although the immobilization process is known to cause shrinkage of the protein and possible modifications of the active site shape and dimension, the proposed biosensor did not show any loss of specificity. Figure 7 shows the current response of the electrode coated with NFM/CNT/GOX after the addition of (1) glucose, followed by sequential addition of other sugars, such as (2) sucrose, (3) maltose, and (4) fructose (followed by a second addition of glucose).

The resulting signal of these interferents is limited to a negligible current decrease, which is consistent with the dilution factor consequent to the addition of a volume of solvent. After a further addition of glucose (point 5), the signal rose again consistently as the first spike, demonstrating that the presence of other sugars does not affect the current response to glucose. The maintenance of the initial specificity of GOX toward common sugars gives proof that the enzyme has not changed morphology during the immobilization procedure. We took into account other possible interferents, 


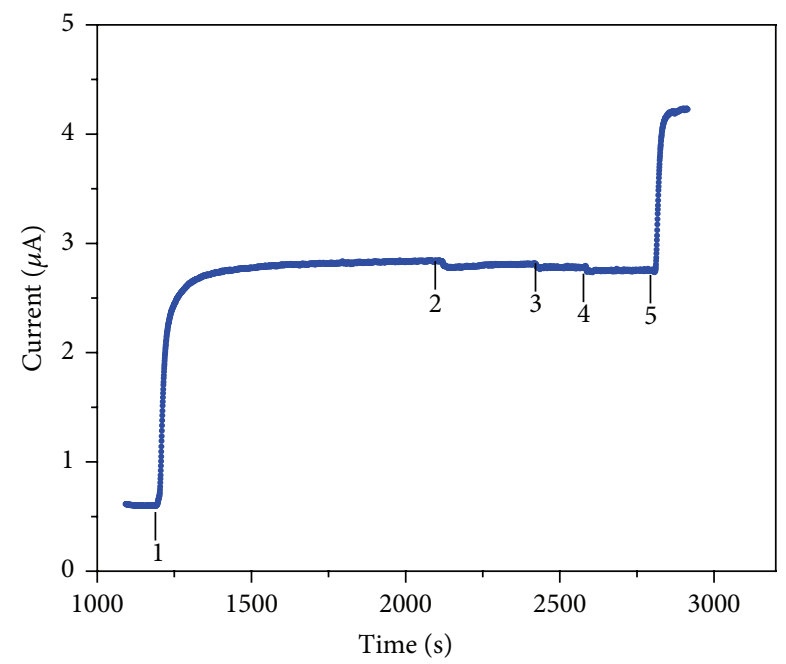

FIGURE 7: Chronoamperometry analysis of possible interferents. The numbers indicate addition points where there are (1) $50 \mu \mathrm{L} 0.5 \mathrm{M}$ glucose addition ( $2.5 \mathrm{mM}$ final concentration), (2) $101.5 \mu \mathrm{L} 0.5 \mathrm{M}$ saccharose ( $5 \mathrm{mM}$ final concentration), (3) $101.5 \mu \mathrm{L} 0.5 \mathrm{mM}$ fructose ( $5 \mathrm{mM}$ final concentration), (4) $101.5 \mu \mathrm{L} 0.5 \mathrm{mM}$ maltose $(5 \mathrm{mM}$ final concentration), and (5) $50 \mu \mathrm{L} 0.5 \mathrm{M}$ glucose addition $(5 \mathrm{mM}$ final concentration). Measurements were taken at day 45 in $100 \mu \mathrm{M}$ Ferrocene methanol in BR buffer $\mathrm{pH}$ 5.0.

namely, phenolic acids and ascorbic acid. Both can theoretically contribute to the signal by direct oxidation at the anode at potential below $0.5 \mathrm{~V}$. We measured a contribution of $2.8 \mu \mathrm{A} \mathrm{mM}^{-1}$ gallic acid spiked in the experimental conditions (immobilized GOX, $100 \mu \mathrm{M}$ ferrocene methanol, and Britton-Robinson buffer $\mathrm{pH}$ 5). However, the reported concentrations of this class of antioxidants in beer are some order of magnitude smaller [57]. For ascorbic acid instead, the response of spiked amounts in the set conditions was slightly higher $\left(3 \mu \mathrm{A} \mathrm{mM}^{-1}\right)$; we found few references on its presence in beer. For example, in commercial beers the ascorbic acid concentrations allowed are $<10 \mathrm{mg} \mathrm{kg}^{-1}(58 \mu \mathrm{M})$ [58]. Moreover, each aliquot of beer sample was diluted in the measurement cell by a 1:100 dilution factor. As a further precaution during beer samples analyses we left the sample to equilibrate at room temperature before and after filtration, to equilibrate oxygen content that acts as oxidizing agent for ascorbic acid.

The stability of the biosensor over time was monitored by repeating the glucose calibration, in the same condition, within 30 days from the first test. The results are reported in Figure 8.

The loss of efficiency of the biosensor has been monitored over one month and the results of the first 26-day period are reported as overall loss of plateau END currents (analogue to MM $V_{\text {MAX }}$, evaluated by Hill model fitting). Over one month it has been the $19 \%$. Notably, the change is almost completely concentrated in the first 15 days and was almost negligible for the next 11 days (day 15 to day 26).

3.4. Biosensing of Glucose in Commercial Beverage and Beer Production Monitoring. The proposed biosensor was firstly

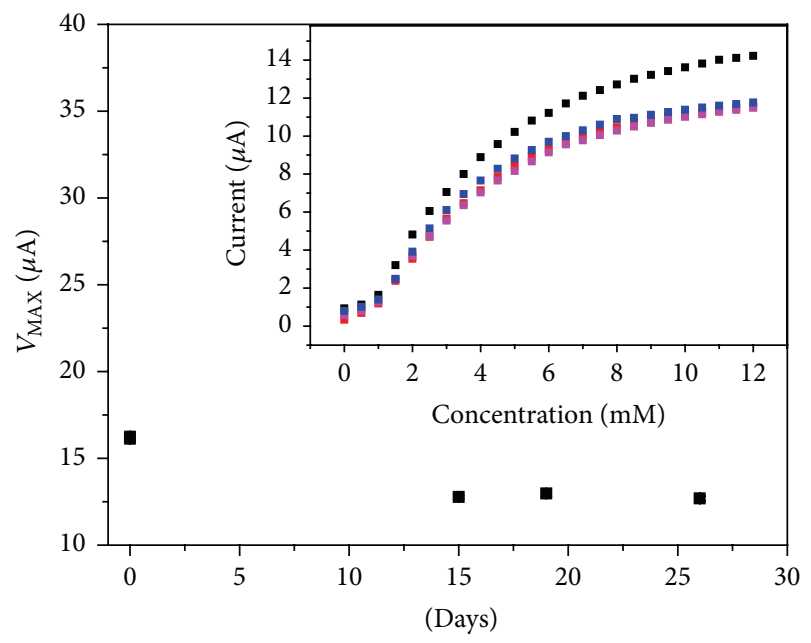

FIGURE 8: Main graph: plateau END values versus time/day, obtained by Hill fitting (day 0 to day 26). Inset: correspondent chronoamperometry plateau currents at each addition. Modified GC working electrode was stored in a $\mathrm{pH} 5$ buffered solution at $4^{\circ} \mathrm{C}$ over 26 days. Conditions used: $100 \mu \mathrm{M}$ ferrocene methanol in $400 \mathrm{mM}$ Britton-Robinson buffer $\mathrm{pH} 5 ;+0.5 \mathrm{~V}$ applied potential; 1 point/sec; constant $10 \mu \mathrm{L}$ additions.

tested on a commercial beverage and then to monitor a brewing process. In both cases, an aliquot of the selected beverage or wort (at each preparation stage) was added to $10 \mathrm{~mL}$ of Britton-Robinson buffer solution ( $0.4 \mathrm{M}, \mathrm{pH} 5)$, where ferrocene methanol $(100 \mu \mathrm{M})$ had been dissolved. For the commercial energy drink (Energade Orange flavor), the results where comparable with those obtained by the dinitrosalicylic acid (DNS, calibration reported in SI) assay. DNS test (see calibration curve employed in the Supporting Information, Figure SI 3) indicated a glucose concentration value of $0.3 \pm 0.1 \mathrm{~g} \cdot 100 \mathrm{~mL}^{-1}$ which is in perfect agreement with the result obtained with the biosensor of $0.297 \pm 0.007 \mathrm{~g} \cdot 100 \mathrm{~mL}^{-1}$. Notably, the measurements were performed in three replicates both for DNS and with the biosensor. The latter gave a much higher precision in terms of percentage error, namely, $33 \%$ for DNS and $2.3 \%$ for the biosensor. Then we applied the prepared biosensor to the analysis of the brewing process.

Figure 9 shows the current response obtained with the NFM/CNT/GOX biosensor during the beer brewing process. At the early steps of mashing (from (1) to (5)), the concentration of glucose sharply increased, reaching a plateau value at about $0.3 \mathrm{~g} \cdot 100 \mathrm{~mL}^{-1}$. In step (6), the wort was washed to recover the leftover sugars $(500 \mathrm{~mL})$. The data were corrected to account for this dilution. During the fermentation the concentration of glucose dropped significantly, until the fourth day of fermentation, when the yeast has consumed almost all the glucose present in the wort.

\section{Conclusions}

GOX-NFM/MWCNT showed a good reproducibility over more than one month of utilization. This system is endowed 


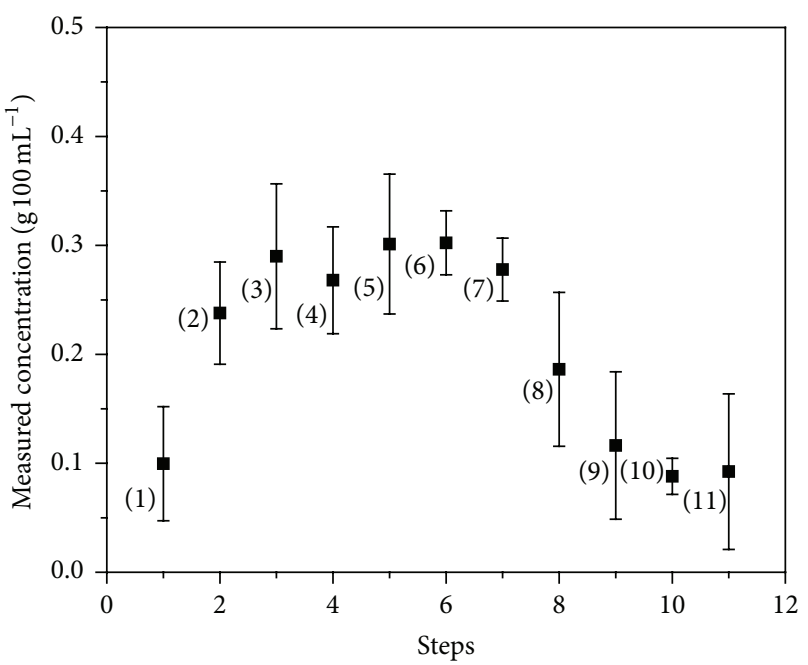

FIGURE 9: Chronoamperometric analysis performed on filtered $(0.2 \mu \mathrm{m}$ filter $)$ wort samples taken at different process times. 1000 or $1500 \mu \mathrm{L}$ was added to $10 \mathrm{~mL} 400 \mathrm{mM}$ Britton-Robinson buffer $\mathrm{pH}$ 5. Dilution factors were taken into account for concentration calculation. Measurements were repeated in triplicate. Summary of analyzed steps: (1) addition of the malt in water $\left(52^{\circ} \mathrm{C}\right)$; (2) protease rest $\left(52^{\circ} \mathrm{C}\right.$ for $\left.15 \mathrm{~min}\right)$; (3) maltose production $\left(62^{\circ} \mathrm{C}\right.$ for $10 \mathrm{~min})$; (4) saccharification $\left(68^{\circ} \mathrm{C}\right.$ for $\left.30 \mathrm{~min}\right)$; (5) deactivation of the enzymes ( $78^{\circ} \mathrm{C}$ for $15 \mathrm{~min}$ ); (6) filtration of the wort and washing with water (about $500 \mathrm{~mL}$ ); (7) addition of the hops and boiling (for $1 \mathrm{~h}$ ) followed by removing the hops and cooling down to room temperature at which the yeast was added; (8) fermentation: day 1 ; (9) fermentation: day 2; (10) fermentation: day 3; (11) fermentation: day 4 .

with qualities such as a very low cost of production, storage resistance, and fast response time in the linear range (10$20 \mathrm{~s}$ ). Moreover, it displays complementarity with other more classical analytical methods such as DNS and Brix. Together, they allow investigating the evolution of glucose with respect to other sugars. Still, both DNS and Brix are not sufficient to account for the evolution of specific sugar in matrices as complex as beer. Conversely, the biosensor shows a complete insensitivity toward other mono- and oligosaccharides even at concentration equal to or higher than glucose. The sensitivity of the biosensor in the linear range was evaluated to be $12 \mu \mathrm{A} \cdot \mathrm{mM}^{-1}$ with an evaluated limit of quantitation of $20 \mu \mathrm{M}$. Moreover, the kinetics of the immobilized GOX was evaluated with respect to free GOX. Michaelis-Menten model failed to actually fit the data; therefore the more general Hill equation was employed. Notably, the same effect was not observed with free GOX, where MM could be successfully applied. As future developments, the enzyme life and the enzymatic performances could be extended by preventing detachment from the nylon NMF. This research has demonstrated the suitability of the proposed biosensor for the monitoring of very complex fluids such as those deriving from the brewing process. Accordingly, the findings of this study may pave the way to a number of important applications for future practice. For instance, the proposed biosensor will be useful in the quantification of glucose in fruit juice [59], in fermentation process of fruit must [60], or even in the development of electronic tongue method for the objective evaluation of sweetness in beverages [61]. The possible applicability of the biosensor seems limited only by the presence of other redox species, such as ascorbic acid, that, when present at high concentrations, may interfere with the mediated biosensing mechanism. However, even in such unfavorable circumstance, the detection of glucose is still possible, provided that the sample is thoroughly aerated before the analysis, as ascorbic acid reacts quickly and irreversibly with oxygen.

\section{Competing Interests}

The authors declare no competing interests related to the publication of this paper.

\section{References}

[1] S. B. Bankar, M. V. Bule, R. S. Singhal, and L. Ananthanarayan, "Glucose oxidase-an overview," Biotechnology Advances, vol. 27, no. 4, pp. 489-501, 2009.

[2] R. Wilson and A. P. F. Turner, "Glucose oxidase: an ideal enzyme," Biosensors and Bioelectronics, vol. 7, no. 3, pp. 165-185, 1992.

[3] J. Wang, "Electrochemical glucose biosensors," Chemical Reviews, vol. 108, no. 2, pp. 814-825, 2008.

[4] P. Martinkova and M. Pohanka, "Biosensors for blood glucose and diabetes diagnosis: evolution, construction, and current status," Analytical Letters, vol. 48, no. 16, pp. 2509-2532, 2015.

[5] A. Harper and M. R. Anderson, "Electrochemical glucose sensors-developments using electrostatic assembly and carbon nanotubes for biosensor construction," Sensors, vol. 10, no. 9, pp. 8248-8274, 2010.

[6] M. Scampicchio, A. Arecchi, A. Bianco, A. Bulbarello, C. Bertarelli, and S. Mannino, "Nylon nanofibrous biosensors for glucose determination," Electroanalysis, vol. 22, no. 10, pp. 10561060, 2010.

[7] J. Wang, "Carbon-nanotube based electrochemical biosensors: a review," Electroanalysis, vol. 17, no. 1, pp. 7-14, 2005.

[8] M. Liu, R. Liu, and W. Chen, "Graphene wrapped $\mathrm{Cu}_{2} \mathrm{O}$ nanocubes: Non-enzymatic electrochemical sensors for the detection of glucose and hydrogen peroxide with enhanced stability, Biosensors and Bioelectronics, vol. 45, no. 1, pp. 206212, 2013.

[9] H. Wang, Y. Bu, W. Dai, K. Li, H. Wang, and X. Zuo, "Welldispersed cobalt phthalocyanine nanorods on graphene for the electrochemical detection of hydrogen peroxide and glucose sensing," Sensors and Actuators B: Chemical, vol. 216, Article ID 18349, pp. 298-306, 2015.

[10] H. Hu, M. Feng, and H. Zhan, "A glucose biosensor based on partially unzipped carbon nanotubes," Talanta, vol. 141, pp. 6672, 2015.

[11] R. Devasenathipathy, V. Mani, S.-M. Chen et al., "Glucose biosensor based on glucose oxidase immobilized at gold nanoparticles decorated graphene-carbon nanotubes," Enzyme and Microbial Technology, vol. 78, pp. 40-45, 2015.

[12] C. Bourdillon, C. Demaille, J. Moiroux, and J.-M. Savéant, "New insights into the enzymatic catalysis of the oxidation of glucose by native and recombinant glucose oxidase mediated by electrochemically generated one-electron redox cosubstrates," 
Journal of the American Chemical Society, vol. 115, no. 1, pp. 210, 1993.

[13] S. Vogt, M. Schneider, H. Schäfer-Eberwein, and G. Nöll, "Determination of the $\mathrm{pH}$ dependent redox potential of glucose oxidase by spectroelectrochemistry," Analytical Chemistry, vol. 86, no. 15, pp. 7530-7535, 2014.

[14] C. Cannes, F. Kanoufi, and A. J. Bard, "Cyclic voltammetry and scanning electrochemical microscopy of ferrocenemethanol at monolayer and bilayer-modified gold electrodes," Journal of Electroanalytical Chemistry, vol. 547, no. 1, pp. 83-91, 2003.

[15] H. Yang, R. Yuan, Y. Chai et al., "Electrochemical immunosensor for human chorionic gonadotropin based on horseradish peroxidase-functionalized Prussian blue-carbon nanotubes/ gold nanocomposites as labels for signal amplification," Electrochimica Acta, vol. 56, no. 5, pp. 1973-1980, 2011.

[16] A. R. Gonalves, M. E. Ghica, and C. M. A. Brett, "Preparation and characterisation of poly(3,4-ethylenedioxythiophene) and poly(3,4-ethylenedioxythiophene)/poly(neutral red) modified carbon film electrodes, and application as sensors for hydrogen peroxide," Electrochimica Acta, vol. 56, no. 10, pp. 3685-3692, 2011.

[17] A. A. Homaei, R. Sariri, F. Vianello, and R. Stevanato, "Enzyme immobilization: an update," Journal of Chemical Biology, vol. 6, no. 4, pp. 185-205, 2013.

[18] V. Goornavar, R. Jeffers, S. Biradar, and G. T. Ramesh, "Utilization of highly purified single wall carbon nanotubes dispersed in polymer thin films for an improved performance of an electrochemical glucose sensor," Materials Science and Engineering: C, vol. 40, pp. 299-307, 2014.

[19] S. A. Kumar and S.-M. Chen, "Electrocatalytic reduction of oxygen and hydrogen peroxide at poly(p-aminobenzene sulfonic acid)-modified glassy carbon electrodes," Journal of Molecular Catalysis A: Chemical, vol. 278, no. 1-2, pp. 244-250, 2007.

[20] D. N. Tran and K. J. Balkus, "Enzyme immobilization via electrospinning," Topics in Catalysis, vol. 55, no. 16, pp. 10571069, 2012.

[21] A. Rekuć, P. Kruczkiewicz, B. Jastrzembska, J. Liesiene, W. Peczyńska-Czoch, and J. Bryjak, "Laccase immobilization on the tailored cellulose-based Granocel carriers," International Journal of Biological Macromolecules, vol. 42, no. 2, pp. 208-215, 2008.

[22] A. Sassolas, L. J. Blum, and B. D. Leca-Bouvier, "Immobilization strategies to develop enzymatic biosensors," Biotechnology Advances, vol. 30, no. 3, pp. 489-511, 2012.

[23] Q. Feng, B. Tang, Q. Wei, D. Hou, S. Bi, and A. Wei, "Preparation of a $\mathrm{Cu}(\mathrm{II})-\mathrm{PVA} / \mathrm{PA} 6$ composite nanofibrous membrane for enzyme immobilization," International Journal of Molecular Sciences, vol. 13, no. 10, pp. 12734-12746, 2012.

[24] Y. Wang, Z. Wang, Y. Rui, and M. Li, "Horseradish peroxidase immobilization on carbon nanodots/CoFe layered double hydroxides: direct electrochemistry and hydrogen peroxide sensing," Biosensors and Bioelectronics, vol. 64, pp. 57-62, 2015.

[25] A. K. Upadhyay, Y.-Y. Peng, and S.-M. Chen, "Immobilization of horseradish peroxidase and nile blue into the ormosil nanocomposite for the fabrication of hydrogen peroxide biosensor based on MWCNT modified glassy carbon electrode," Sensors and Actuators B: Chemical, vol. 141, no. 2, pp. 557-565, 2009.

[26] A. Merkoçi, M. Pumera, X. Llopis, B. Pérez, M. Del Valle, and S. Alegret, "New materials for electrochemical sensing VI: carbon nanotubes," TrAC Trends in Analytical Chemistry, vol. 24, no. 9, pp. 826-838, 2005.
[27] A. T. Lawal, "Synthesis and utilization of carbon nanotubes for fabrication of electrochemical biosensors," Materials Research Bulletin, vol. 73, pp. 308-350, 2016.

[28] S. Kumar, W. Ahlawat, R. Kumar, and N. Dilbaghi, "Graphene, carbon nanotubes, zinc oxide and gold as elite nanomaterials for fabrication of biosensors for healthcare," Biosensors and Bioelectronics, vol. 70, pp. 498-503, 2015.

[29] J. Yan, T. Wu, Z. Ding, and X. Li, "Preparation and characterization of carbon nanotubes/chitosan composite foam with enhanced elastic property," Carbohydrate Polymers, vol. 136, pp. 1288-1296, 2016.

[30] L. D. Tijing, C.-H. Park, W. L. Choi et al., "Characterization and mechanical performance comparison of multiwalled carbon nanotube/polyurethane composites fabricated by electrospinning and solution casting," Composites Part B: Engineering, vol. 44, no. 1, pp. 613-619, 2013.

[31] P. Agnihotri, S. Basu, and K. K. Kar, "Effect of carbon nanotube length and density on the properties of carbon nanotube-coated carbon fiber/polyester composites," Carbon, vol. 49, no. 9, pp. 3098-3106, 2011.

[32] M. V. Jose, B. W. Steinert, V. Thomas et al., "Morphology and mechanical properties of Nylon 6/MWNT nanofibers," Polymer, vol. 48, no. 4, pp. 1096-1104, 2007.

[33] Z.-M. Huang, Y.-Z. Zhang, M. Kotaki, and S. Ramakrishna, "A review on polymer nanofibers by electrospinning and their applications in nanocomposites," Composites Science and Technology, vol. 63, no. 15, pp. 2223-2253, 2003.

[34] A. Macagnano, E. Zampetti, and E. Kny, Electrospinning for High Performance Sensors, NanoScience and Technology, Springer, Berlin, Germany, 2015.

[35] T. Subbiah, G. S. Bhat, R. W. Tock, S. Parameswaran, and S. S. Ramkumar, "Electrospinning of nanofibers," Journal of Applied Polymer Science, vol. 96, no. 2, pp. 557-569, 2005.

[36] N. Bhardwaj and S. C. Kundu, "Electrospinning: a fascinating fiber fabrication technique," Biotechnology Advances, vol. 28, no. 3, pp. 325-347, 2010.

[37] R. Monošík, P. Magdolen, M. Stred'anský, and E. Šturdík, "Monitoring of monosaccharides, oligosaccharides, ethanol and glycerol during wort fermentation by biosensors, HPLC and spectrophotometry," Food Chemistry, vol. 138, no. 1, pp. 220-226, 2013.

[38] M. I. Prodromidis and M. I. Karayannis, "Enzyme based amperometric biosensors for food analysis," Electroanalysis, vol. 14, no. 4, pp. 241-261, 2002.

[39] I. E. Tothill, J. D. Newman, S. F. White, and A. P. F. Turner, "Monitoring of the glucose concentration during microbial fermentation using a novel mass-producible biosensor suitable for on-line use," Enzyme and Microbial Technology, vol. 20, no. 8, pp. 590-596, 1997.

[40] J. P. Favier, D. Bicanic, P. Helander, and M. Van Iersel, "The optothermal approach to a real time monitoring of glucose content during fermentation by brewers' yeast," Journal of Biochemical and Biophysical Methods, vol. 34, no. 3, pp. 205-211, 1997.

[41] P. Mauri, M. Minoggio, P. Simonetti, C. Gardana, and P. Pietta, "Analysis of saccharides in beer samples by flow injection with electrospray mass spectrometry," Rapid Communications in Mass Spectrometry, vol. 16, no. 8, pp. 743-748, 2002.

[42] R. A. S. Lapa, J. L. F. C. Lima, and I. V. O. S. Pinto, "Development of a sequential injection analysis system for the simultaneous biosensing of glucose and ethanol in bioreactor fermentation," Food Chemistry, vol. 81, no. 1, pp. 141-146, 2003. 
[43] L. C. Nogueira, F. Silva, I. M. P. L. V. O. Ferreira, and L. C. Trugo, "Separation and quantification of beer carbohydrates by high-performance liquid chromatography with evaporative light scattering detection," Journal of Chromatography A, vol. 1065, no. 2, pp. 207-210, 2005.

[44] J. Li, J. Yu, F. Zhao, and B. Zeng, "Direct electrochemistry of glucose oxidase entrapped in nano gold particles-ionic liquid- $N, N$ dimethylformamide composite film on glassy carbon electrode and glucose sensing," Analytica Chimica Acta, vol. 587, no. 1, pp. 33-40, 2007.

[45] B. H. Clowers, E. D. Dodds, R. R. Seipert, and C. B. Lebrilla, "Dual polarity accurate mass calibration for electrospray ionization and matrix-assisted laser desorption/ionization mass spectrometry using maltooligosaccharides," Analytical Biochemistry, vol. 381, no. 2, pp. 205-213, 2008.

[46] R. Lehnert, P. Novák, F. Macieira, M. Kuřec, J. A. Teixeira, and T. Brányik, "Optimisation of lab-scale continuous alcohol-free beer production," Czech Journal of Food Sciences, vol. 27, no. 4, pp. 267-275, 2009.

[47] M. Tamura, A. Takahashi, A. Uyama, and N. Mochizuki, "Simultaneous analysis for carbohydrates in drinks by high performance liquid chromatography with charged aerosol detector," Bunseki Kagaku, vol. 59, no. 3, pp. 239-245, 2010.

[48] O. O. Soldatkin, V. M. Peshkova, O. Y. Saiapina et al., "Development of conductometric biosensor array for simultaneous determination of maltose, lactose, sucrose and glucose," Talanta, vol. 115, pp. 200-207, 2013.

[49] S. Rakete and M. A. Glomb, "A novel approach for the quantitation of carbohydrates in mash, wort, and beer with RP-HPLC using 1-naphthylamine for precolumn derivatization," Journal of Agricultural and Food Chemistry, vol. 61, no. 16, pp. 3828-3833, 2013.

[50] A. J. Das, P. Khawas, T. Miyaji, and S. C. Deka, "HPLC and GCMS analyses of organic acids, carbohydrates, amino acids and volatile aromatic compounds in some varieties of rice beer from northeast India," Journal of the Institute of Brewing, vol. 120, no. 3, pp. 244-252, 2014.

[51] R. Monošík, M. Stred'anský, K. Lušpai, P. Magdolen, and E. Šturdík, "Amperometric glucose biosensor utilizing FADdependent glucose dehydrogenase immobilized on nanocomposite electrode," Enzyme and Microbial Technology, vol. 50, no. 4-5, pp. 227-232, 2012.

[52] G. L. Miller, "Use of dinitrosalicylic acid reagent for determination of reducing sugar," Analytical Chemistry, vol. 31, no. 3, pp. 426-428, 1959.

[53] A. Guiseppi-Elie, C. Lei, and R. H. Baughman, "Direct electron transfer of glucose oxidase on carbon nanotubes," Nanotechnology, vol. 13, no. 5, pp. 559-564, 2002.

[54] V. Mani, B. Dinesh, S.-M. Chen, and R. Saraswathi, "Direct electrochemistry of myoglobin at reduced graphene oxidemultiwalled carbon nanotubes-platinum nanoparticles nanocomposite and biosensing towards hydrogen peroxide and nitrite," Biosensors and Bioelectronics, vol. 53, pp. 420-427, 2014.

[55] F. Arslan, S. Ustabaş, and H. Arslan, "An amperometric biosensor for glucose determination prepared from glucose oxidase immobilized in polyaniline-polyvinylsulfonate film," Sensors, vol. 11, no. 8, pp. 8152-8163, 2011.

[56] D. Patil, N. Q. Dung, H. Jung, S. Y. Ahn, D. M. Jang, and D. Kim, "Enzymatic glucose biosensor based on $\mathrm{CeO}_{2}$ nanorods synthesized by non-isothermal precipitation," Biosensors and Bioelectronics, vol. 31, no. 1, pp. 176-181, 2012.
[57] L. Montanari, G. Perretti, F. Natella, A. Guidi, and P. Fantozzi, "Organic and phenolic acids in beer," LWT-Food Science and Technology, vol. 32, no. 8, pp. 535-539, 1999.

[58] E. Food and S. Authority, "Scientific Opinion on the reevaluation of ascorbic acid (E 300), sodium ascorbate (E 301) and calcium ascorbate (E 302) as food additives," EFSA Journal, vol. 13, no. 5, pp. 1-124, 2015.

[59] M. Scampicchio, A. Arecchi, N. S. Lawrence, and S. Mannino, "Nylon nanofibrous membrane for mediated glucose biosensing," Sensors and Actuators, B: Chemical, vol. 145, no. 1, pp. 394$397,2010$.

[60] S. Piermarini, G. Volpe, M. Esti, M. Simonetti, and G. Palleschi, "Real time monitoring of alcoholic fermentation with low-cost amperometric biosensors," Food Chemistry, vol. 127, no. 2, pp. 749-754, 2011.

[61] A. Bulbarello, M. Cuenca, L. Schweikert, S. Mannino, and M. Scampicchio, "Hybrid E-tongue for the evaluation of sweetness and bitterness of soft drinks fortified with epigallocatechin gallate," Electroanalysis, vol. 24, no. 10, pp. 1989-1994, 2012. 

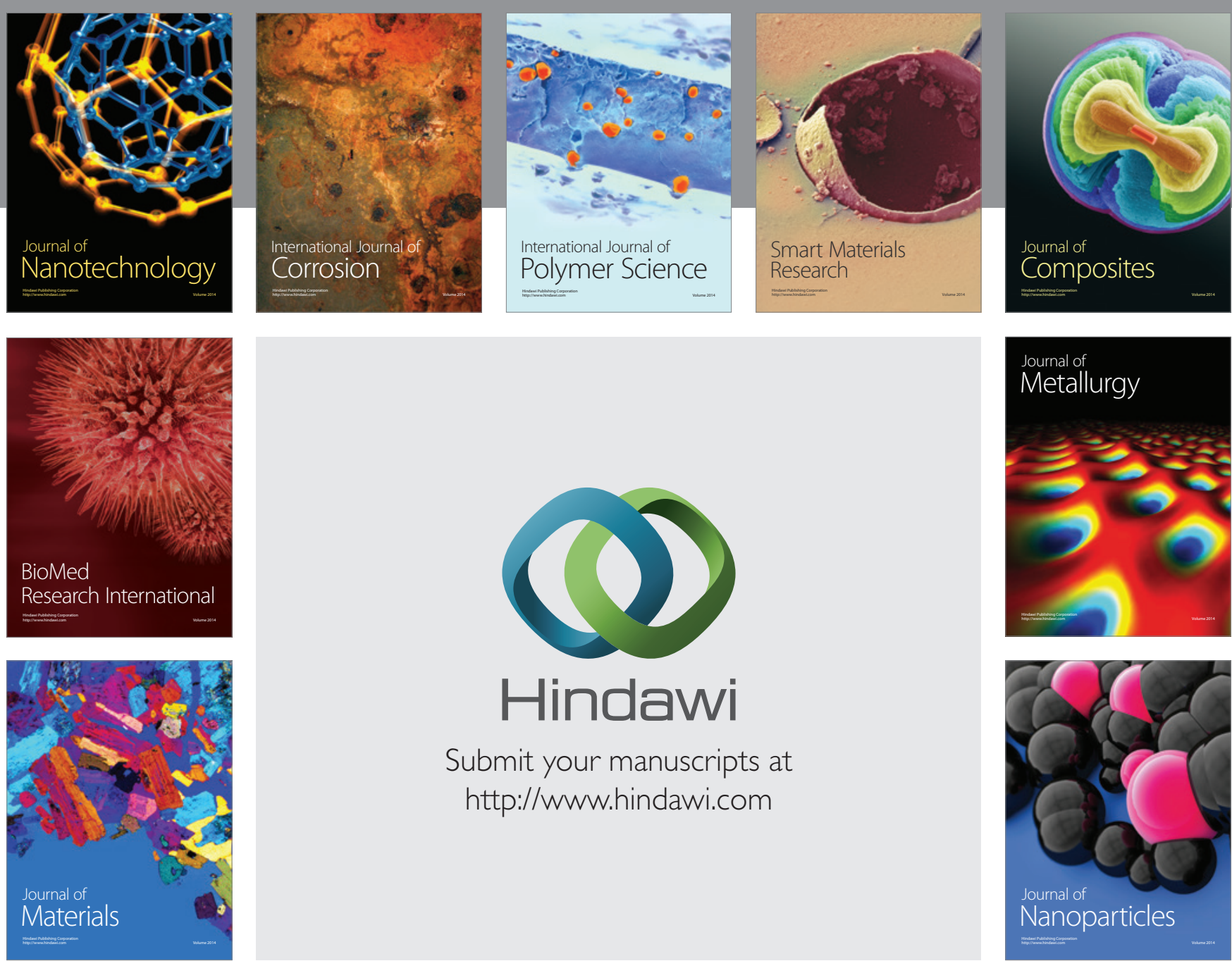

\section{Hindawi}

Submit your manuscripts at

http://www.hindawi.com

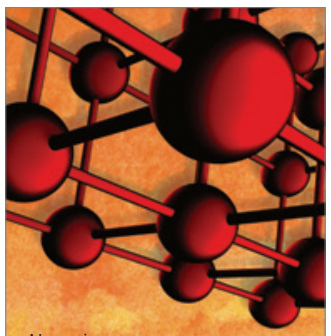

Materials Science and Engineering
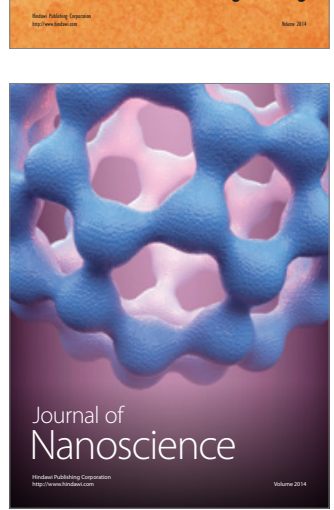
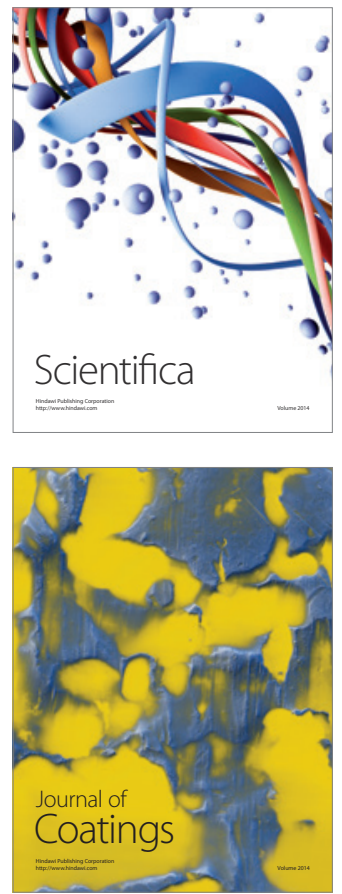
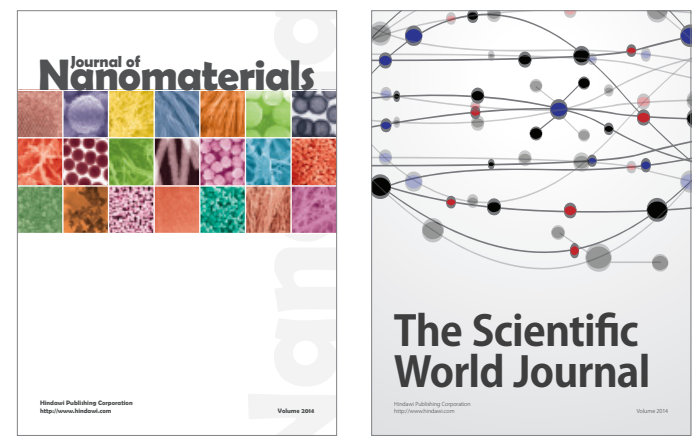

The Scientific World Journal
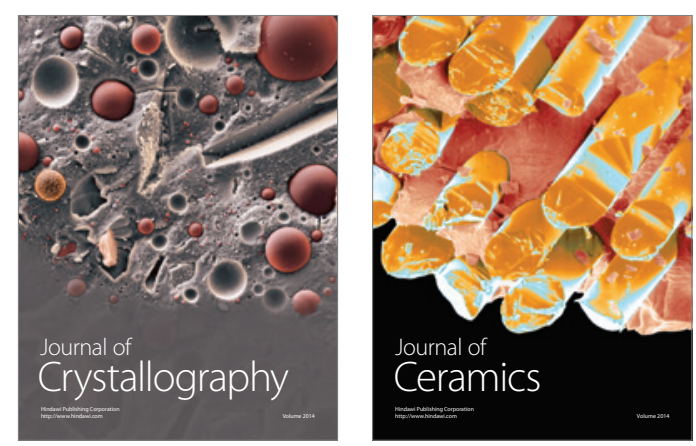
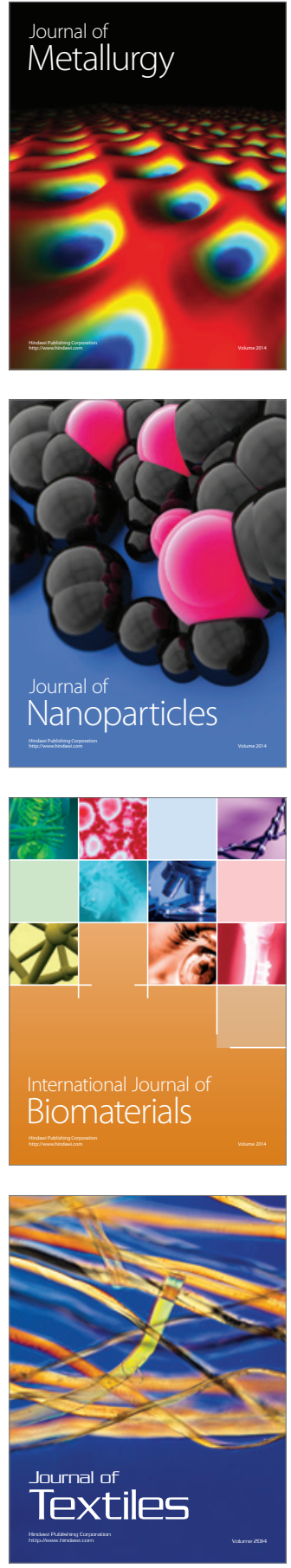